\title{
Asian Journal of Pharmaceutical Research and Development
}

(An International Peer-Reviewed Journal of Pharmaceutical Research and Development) (c) 2013-18, publisher and licensee AJPRD, This is an Open Access article which permits unrestricted non-commercial use, provided the original work is properly cited

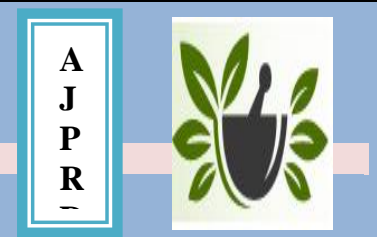

Open $\odot$ Access

Available online at http://ajprd.com/index.php

Research Article

\section{PATTERN OF ADVERSE DRUG REACTIONS AND ITS MANAGEMENT IN FEMALE CANCER PATIENTS IN A PRIVATE HOSPITAL IN TELANGANA, INDIA}

\author{
G.Meghana1, B.Pratap reddy ${ }^{2}$, K.V.Raghavaiah ${ }^{2}$, D.Sudheer kumar3, P.Kishore ${ }^{{ }^{*}}$ \\ ${ }^{1}$ Department of Pharmacy Practice, Care College of Pharmacy, Oglapur (v), Damera (m), Warangal, India \\ ${ }^{2}$ Department of Oncology, St.Ann's Hospital, Oglapur (v), Damera (m), Warangal,India \\ 3Department of Pharmaceutics, Care College of Pharmacy, Oglapur (v), Damera (m), Warangal, India
}

\begin{abstract}
Chemotherapy and radiation are one of the important components of treatment for many cancers. Anti-neoplastic agents are used with caution due to their high toxicity and narrow therapeutic window. Studies describing pattern of adverse drug reactions in cancer chemotherapy and radiation therapy patients are less in India. This study aims to evaluate the pattern of ADR's due to cancer chemotherapy and radiation therapy in hospitalized patients and to assess the causality and severity of these reactions in Telangana state, India. This was a prospective observational study conducted in a private hospital in Telangana region from January to august. Two thousand three hundred and forty two ADR's were recorded from 254 patients. Most common ADR's were vomiting $(10.7 \%)$, nausea $(10.7 \%)$ and fatigue $(10.7 \%)$. Majority of the ADR's $(53.5 \%)$ were affecting the Gastro-intestinal system. Naranjo scale for causality assessment showed $54.3 \%$ of the reaction to be "definite", $36.8 \%$ to be "probable". Modified Hartwig and Siegel scale for severity showed most reaction ( $84.1 \%)$ to be of "moderate level", while $13.3 \%$ of reactions were of "mild level". There is an immediate need to create awareness among health care professionals regarding the importance of the pharmacovigilance system. Use of preventive measures is to be enhanced in order to reduce the incidence and severity of ADR's. This study showed most ADR's are preventable with effective ADR monitoring.
\end{abstract}

Keywords: Adverse drug reaction (ADR), ADR monitoring, Pharmacovigilance, chemotherapy, radiation therapy.

Article Info: Received 25 July, 2018;

Review Completed 16 Aug 2018;

Accepted 20 Aug 2018

Cite this article as:

Kishore.P, Pattern of Adverse Drug Reactions and Its Management in Female Cancer Patients in a Private Hospital in Telangana, India,Asian Journal of Pharmaceutical research and Development.2018;6 (4): 45-53

DOI: http://dx.doi.org/10.22270/ajprd.v6.i4.381

\section{*Address for Correspondence}

Dr.P.Kishore ,Head, Department of Pharmacy Practice, Care College of Pharmacy, Care College of Pharmacy,Oglapur (v), Damera (m), Warangal

\section{INTRODUCTION:}

$\mathrm{C}$ ancer is a major cause of morbidity and mortality in developing and developed countries. In many low-income and middleincome countries, including India, most of the population does not have access to a well organized and well regulated cancer care system. The diagnosis of cancer often leads to catastrophic personal health expenditures. Such expenditures can push entire families below the poverty line and may threaten social stability [1]. During the last 20 years, India has emerged as a fast growing economy with changes in life style relatedbehaviour partially responsible for the increasing cancer burden. Such global transitions are also associated with less favourable consequences including the increasing prospects of, and accessibility to, unhealthy lifestyle behaviours, including tobacco use, increased consumption of highly calorific foods and a reduction in physical activity [2]. Chemotherapy, radiotherapy, surgery, hormonal therapy, immunotherapy, biologic therapy and cryosurgery are the different treatment modalities available for cancer. Chemotherapy is an important component of treatment for many cancers, and new anti-cancer drugs represent one of the largest areas of pharmaceutical development [3]. Anticancer drugs have narrow therapeutic index, 
adverse drug reactions (ADRs) to these medications are high compared to other classes of drugs. However, the nature of chemotherapy means that while damaging cancer cells it also damages healthy cells, leading to side effects. The side effects of chemotherapy affect an individual's physical health, quality of life and emotional state [4].

Radiation is a physical agent, which is used to destroy cancer cells. Although radiation damages both normal cells as well as cancer cells, the goal of radiation therapy is to maximize the radiation dose to abnormal cancer cells while minimizing exposure to normal cells, which is adjacent to cancer cells or in the path of radiation [5]. According to WHO, adverse drug reaction (ADR) is defined as "any response to a drug which is noxious and unintended and which occurs at doses normally used in man for prophylaxis, diagnosis, or therapy of disease, or for the modification of physiological function."[6]. Attribution of symptoms can be difficult because there can be a lack of clarity concerning what is disease-related, treatment-related, a co-morbid illness or a combination of all three. Additionally, as cancer progresses, both the symptoms and treatments evolve, resulting in a complex, timedependent relationship [7].

Worldwide, ADRs accounted for $10 \%$ of hospital admissions and $6 \%$ of hospitalized patients suffer from ADRs [8]. In a meta-analysis of 39 prospective studies of already hospitalized patients in US hospitals, the incidence of serious ADRs was $6.7 \%$ and of fatal ADRs $0.32 \%$ making ADRs between the fourth and sixth leading cause of death in the USA [9]. Epidemiological exploration performed in the Australia demonstrates $11 \%$ of ADRs in Australian hospitals were connected with anti-neoplastic medications being the most widely recognized operators in charge of solution related hospitalization [10]. In the UK a major study of hospital patients found that up to $6.5 \%$ of admissions were due to ADRs, three-quarters of which were judged preventable [9]. A study conducted in South Indian hospital has reported anti-neoplastic agents as the common class of drugs causing ADRs accounting for a total of $21.8 \%$ of the reported ADRs. A recent study on global patterns of ADRs over a decade has documented that high-income countries have more ADRs from anti-neoplastic and immunemodulating agents [3].

Adverse drug reactions are a major clinical problem, accounting for 2-6\% of all hospital admissions. Recent surveys in the United States have indicated that adverse drug events increase the length of hospital stay and costs [11]. Most of the ADRs with these drugs are unreported due to unawareness of healthcare professionals, lack of time to report and a dearth of sufficient staff in the hospitals. Hence it is necessary to recognize the pattern of ADRs occurring with anticancer drugs so as to enhance the quality of life and to reduce the cost of ADR related hospitalization among cancer patients [3]. The World Health Organization (WHO) expanded the definition of pharmacovigilance to science and activities related to the detection, assessment, understanding, and prevention of adverse effects or any drug related problem [12].The most frequently used pharmacovigilance model, the spontaneous notification of adverse drug reactions (ADRs), has proven inefficient because it usually results in under-reporting [13]. The Pharmacovigilance Program of India (PvPI) is working in collaboration with WHO-Uppsala Monitoring Center, Sweden and contributes the Indian data to the international data base. The PvPI started in year 2010, aims to monitor the adverse drug reactions (ADRs) in Indian population; to create awareness among health-care professionals about the importance of ADR reporting in India; to generate independent, evidence based recommendations on the safety of medicines; and to monitor benefit-risk profile of medicines among others. This program has become very vital as even after so many years of efforts, ADR monitoring is still in infancy in India [14].

Hospital based ADR monitoring and reporting programs can help in identifying an assessing the risks associated with the use of drugs. This data may help the prescribers to identify ADRs and deal with them more efficiently, and also help in preventing the occurrences of these ADRs in future [15].There are patient-related reasons for under reporting like failure to recognise ADR or inability to link the ADR with a drug. The common doctor related reasons are the feeling of guilt, fear of litigation, ignorance, lethargy, inadequate risk perception about newly marketed drugs, diffidence, insufficient training to identify ADRs and lack of awareness about PV program [16].In several countries, pharmacists involved in pharmacovigilance have played an important role in the notification of suspected ADR by providing information and instructions on the safe and appropriate use of medicines, in addition to reducing the prevalence of ADRs and underreporting [17]. This is possible because the pharmacists who directly advise patients, especially within the context of pharmaceutical care, are more likely to detect ADRs. Pharmacovigilance studies are essential in oncology. Antineoplastic agents are well studied and are extremely beneficial in cancer treatment, but they are used with caution due to their high toxicity and narrow therapeutic window [18]. ADRs are so common and predictable in department of oncology that they came around to being accepted as an inevitable component of the treatment [19]. Thus, onco-pharmacovigilance was developed, which is a subsystem of monitoring drugs derived from pharmacovigilance to monitor ADRs to cyto-toxic anti-neoplastic drugs [20]. Pharmacists specialized in oncology are responsible for a wide variety of functions, including monitoring, notification, prevention, and relief of reactions associated with chemotherapy [21]. In a Japanese study, pharmacists were responsible for the prevention and treatment of emesis, peripheral neuropathy, hand- foot syndrome, mucositis, localized pain, constipation, vascular pain, allergy, hyperglycaemia, diarrhoea and other conditions [22]. Lau et al., (2004) studied the preventability of reactions in oncology patients and found that $53 \%$ of the reactions such as alopecia cannot be prevented, whereas $45 \%$ and $2 \%$ of the reactions are probably and definitely preventable, respectively [19].

Studies that shows the incidence of ADRs to chemotherapy are scarce, which hinders the actual 
understanding of their severity and frequency of occurrence in clinical practice. Therefore, studies that report these adverse results can assist the multidisciplinary team in patient education and further suggest preventive procedures and medications. Thus, the adherence to treatment, clinical condition, and response to chemotherapy can be improved, reinforcing the existing review studies that suggest alternatives for the prevention and treatment of ADRs induced by chemotherapy [13].

\section{MATERIALS AND METHODS:}

This prospective study was conducted among 254 female patients admitted to oncology ward of cancer hospital, over a period of 8 months, after obtaining the approval of the institutional ethics committee. It was an observational, focused pharmacovigilance study carried out from January 12017 to august 31 2017. Patient related information was collected in a specially designed data collection form. Patients age, sex, diagnosis, suspected drugs causing ADR's, treatment details (dose, frequency, strength, date of starting and stopping), description of the event, onset of adverse event, information on challenge and de-challenge, type of ADR, system affected by the ADRs, outcome of the ADRs and drugs used to manage the ADRs were analyzed [23].All the female patients attending the oncology department were taken. Males are excluded from this study. Causality was assessed using Naranjo's algorithm. The naranjo's algorithm is a questionnairebased scale consisting of ten questions with three types of answers, yes, no or do not know. Scores are given accordingly, and the drug reaction can be classified as definite, probable, possible and doubtful based on the total score. The modified hartwig and siegel scale classify the severity of ADR as mild, moderate, or severe with various levels according to factors such as requirements for change in treatment, duration of hospital stay, and disability produced by the ADR [1].

\section{RESULTS}

Of 254 patients, the mean age group affected was 51-60 years. Majority of the cases reported were of cervical cancer and breast cancer.TNM staging was done for breast cancer and FIGO staging was done for cervical cancer. Out of 254 patients, the most commonly prescribed chemotherapeutic regimen was cisplatin based followed by adriamycin+cyclophosphamide with paclitaxel.
Table 1: Classification of cancers based on organ system affected

\begin{tabular}{|l|l|}
\hline Type of cancer & No. of patients \\
\hline Reproductive cancer & 195 \\
\hline Gastro-intestinal cancer & 31 \\
\hline Respiratory cancer & 2 \\
\hline Endocrine cancer & 3 \\
\hline Head and neck cancer & 19 \\
\hline Brain cancer & 2 \\
\hline Skin cancer & 2 \\
\hline Total cancer cases & 254 \\
\hline
\end{tabular}

Almost $90 \%$ of the cancer cases reported was of reproductive cancers (cervical cancer followed by breast cancer)

Table 2: Distribution based on treatment modality

\begin{tabular}{|l|l|l|}
\hline Type of treatment & Number of patients & \% \\
\hline Chemotherapy & 136 & 53.9 \\
\hline Chemo-radiation & 106 & 41.2 \\
\hline Radiation therapy & 12 & 4.76 \\
\hline Total & 254 & 100 \\
\hline
\end{tabular}

Among 254 patients, majority of the patients were treated with chemotherapy followed by chemoradiation.

Table 3: Distribution based on different chemotherapeutic regimens

\begin{tabular}{|l|l|l|}
\hline $\begin{array}{l}\text { Chemotherapeutic } \\
\text { regimen }\end{array}$ & $\begin{array}{l}\text { Number of } \\
\text { patients }\end{array}$ & \% \\
\hline Cisplatin based regimen & 103 & 40.07 \\
\hline AC+T & 80 & 31.74 \\
\hline 5FU & 6 & 2.38 \\
\hline 5FU+ cisplatin & 10 & 3.96 \\
\hline Carboplatin+paclitaxel & 23 & 9.12 \\
\hline CMF & 1 & 0.39 \\
\hline Cisplatin+MTX+5F & 2 & 0.79 \\
\hline AC+cisplatin & 1 & 0.39 \\
\hline FOLFOX & 8 & 3.17 \\
\hline Etoposide+cisplatin & 5 & 1.98 \\
\hline Mitoxanthone & 2 & 0.79 \\
\hline Dacarbazine+5F & 1 & 0.39 \\
\hline
\end{tabular}

$\mathrm{AC}=$ adriamycin+cyclophosphamide; $\mathrm{T}=$ taxane;5FU $=5$ -

fluorouracil;MTX=methotrexate,

$\mathrm{CMF}=$ cyclophosphamide + methotrexate +5 -fluorouracil; FOLFOX=5fluorouracil+leukovorin+oxaliplatin

Table 5: Distribution of adverse drug reactions on the affected system

\begin{tabular}{|l|c|l|}
\hline Organ system & Number of patients & \% \\
\hline Musculo-skeletal & 406 & 17.3 \\
\hline Gastro-intestinal & 1253 & 53.5 \\
\hline Skin and appendages & 360 & 15.3 \\
\hline Circulatory & 47 & 2 \\
\hline Nervous system & 140 & 5.9 \\
\hline Respiratory & 30 & 1.28 \\
\hline Urinary system & 95 & 4.05 \\
\hline Miscellaneous & 11 & 0.4 \\
\hline Total & 2342 & 100 \\
\hline
\end{tabular}


Out of 2342 collected ADR's more than $53.5 \%$ of the ADR's are affecting the gastro-intestinal system followed by musculoskeletal system and skin and appendages with $17.3 \%$ and $15.3 \%$ respectively.

Table 4: Distribution of adverse drug reactions and its management

\begin{tabular}{|c|c|c|c|}
\hline Adverse effects & Number of patients & $\%$ & Management of ADR \\
\hline Nausea and Vomiting & 252 & 10.7 & Tab ondansetron $4 \mathrm{mg}$ \\
\hline Anorexia & 252 & 10.7 & Syrup.Zincovit (multivitamins) \\
\hline Alopecia & 105 & 4.4 & Caps or wigs \\
\hline Discoloration of skin & 116 & 4.9 & - \\
\hline Pain in limbs & 81 & 3.45 & Tab Paracetamol $500 \mathrm{mg}$ \\
\hline Weight loss & 182 & 7.7 & $\begin{array}{l}\text { Advised to eat balanced diet which is rich in } \\
\text { fresh fruits and vegetables }\end{array}$ \\
\hline Discoloration of nails & 81 & 3.45 & - \\
\hline Abdominal pain & 53 & 2.26 & Tab .Tramadol 50mg \\
\hline Numbness & 12 & 0.5 & - \\
\hline Cough & 12 & 0.5 & $\begin{array}{l}\text { Syp .TUSQ } 5 \mathrm{ml} \text { (dextramethorphan } \\
\text { Hydrobromide IP } 15 \mathrm{mg} \text {, } \\
\text { Chlorpheniramine Maleate IP } 2 \mathrm{mg} \text {, } \\
\text { Phenylephrine Hydrochloride } 5 \mathrm{mg} \text { ) }\end{array}$ \\
\hline Fever & 12 & 0.5 & Tab. Paracetamol $650 \mathrm{mg}$ \\
\hline Cold & 5 & 0.2 & Tab. Fexofenadine $5 \mathrm{mg}$ \\
\hline Anaemia & 18 & 0.7 & $\begin{array}{l}\text { Capsule autrin (ferrous fumerate } 300 \mathrm{mg} \text {,folic } \\
\text { acid } 1.5 \mathrm{mg} \text {,cyanacobalamine } 15 \mathrm{mcg} \text { ) }\end{array}$ \\
\hline Pain at site of radiation & 116 & 4.9 & - \\
\hline Diarrhoea & 183 & 7.81 & $\begin{array}{l}\text { Tab.Metronidazole } 400 \mathrm{mg} \text {, } \\
\text { Lactobacillus } 150 \text { million spores } \\
\text { Tab.Ciprofloxacin 500mg. }\end{array}$ \\
\hline Body pains & 19 & 0.8 & Analgesics (topical), Tab. Paracetamol $650 \mathrm{mg}$ \\
\hline Backache & 21 & 0.8 & Back rest \\
\hline Epigastric pain & 9 & 0.3 & Tab.Pantoprazole 40mg +Domperidone 30mg \\
\hline $\begin{array}{l}\text { Itching in the perianal } \\
\text { region }\end{array}$ & 79 & 3.37 & Gentian violet paint \\
\hline Pain during defecation & 79 & 3.37 & Lignocaine oint $2 \%$ \\
\hline Thrombophlebitis & 58 & 2.47 & $\begin{array}{l}\text { Benzyl nicotinate topical } 2 \mathrm{mg}+\text { Heparin } \\
\text { topical 50IU }\end{array}$ \\
\hline Burning micturition & 16 & 0.6 & $\begin{array}{l}\text { Syrup Potassium citrate } 1100 \mathrm{mg}+\text { magnesium } \\
\text { citrate } 375 \mathrm{mg}+\text { hydrochloride } 20 \mathrm{mg}\end{array}$ \\
\hline Giddiness & 32 & 1.36 & - \\
\hline Headache & 30 & 1.28 & Analgesics (topical) \\
\hline Constipation & 17 & 0.72 & $\begin{array}{l}\text { Syrup.Cremaffin } 5 \mathrm{ml} \text { ( liquid paraffin } 3.75 \mathrm{ml} \text {, } \\
\text { magnesium hydroxide } 11.25 \mathrm{Ml} / 15 \mathrm{~mL} \text { ) } \\
\text { Tab.bisacodyl } 5 \mathrm{mg}\end{array}$ \\
\hline Bleeding & 19 & 0.8 & Inj. Or tablet ethamsylate $250 \mathrm{mg}$ \\
\hline Pedal oedema & 8 & 0.3 & - \\
\hline Throat pain & 11 & 0.46 & - \\
\hline Mouth ulcer & 8 & 0.3 & $\begin{array}{l}\text { Gel Choline salicylate } 9 \% \mathrm{w} / \mathrm{v}+\text { lidocaine } \\
\text { topical } 2 \% \mathrm{w} / \mathrm{v}\end{array}$ \\
\hline Abscess & 1 & 0.04 & - \\
\hline Indigestion & 27 & 1.1 & - \\
\hline Epistaxis & 2 & 0.08 & Tab ethamsylate $250 \mathrm{mg}$ \\
\hline Sleeplessness & 54 & 2.3 & - \\
\hline Dysphagia & 11 & 0.4 & - \\
\hline Eye pain & 5 & 0.2 & - \\
\hline Fatigue & 252 & 10.7 & $\begin{array}{l}\text { Diet modifications, if not subsided, IV } \\
\text { hydration }\end{array}$ \\
\hline Chest pain & 91 & 3.8 & - \\
\hline SOB & 10 & 0.4 & Bed elevation \\
\hline Hoarseness of voice & 3 & 0.1 & - \\
\hline Total & 2342 & 100 & - \\
\hline
\end{tabular}




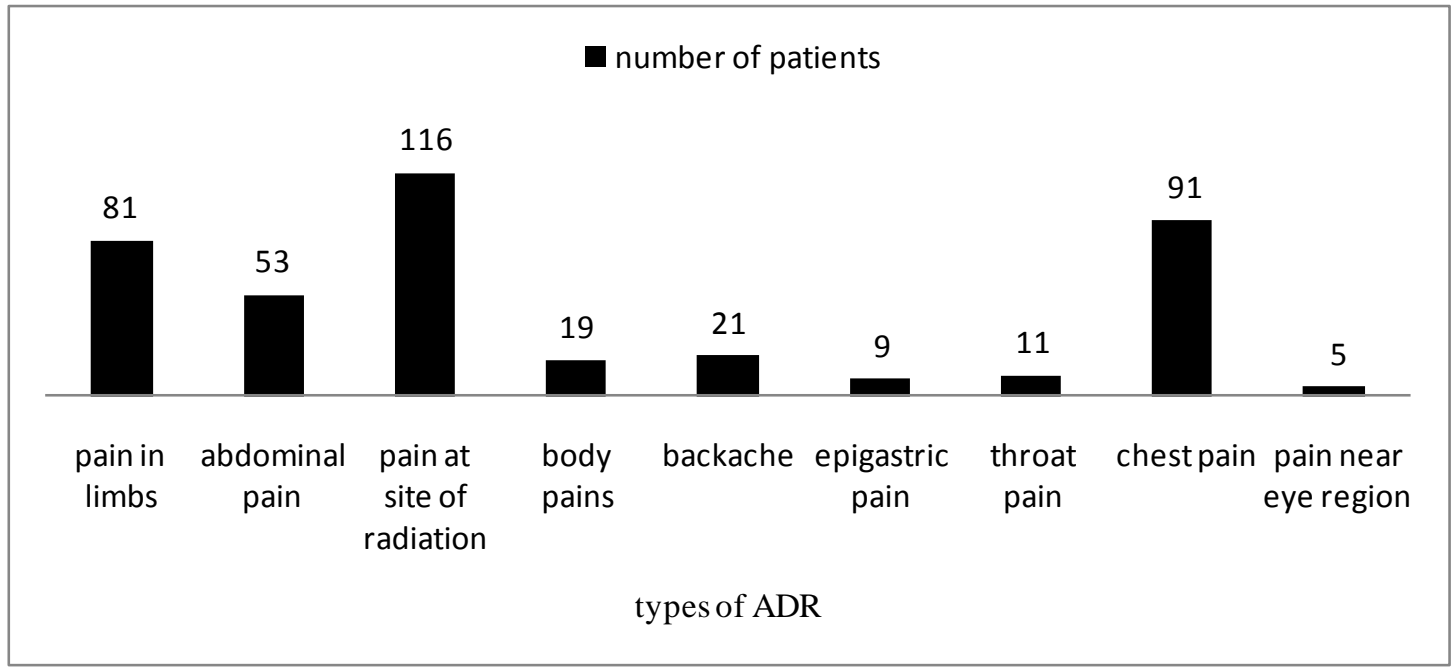

Fig 1: ADR's affecting Musculo-skeletal system

Out of 406 adverse drug reactions affecting pain at the site of radiation followed by chest pain and musculoskeletal system, $28.5 \%$ of patients developed pain in limbs with $22.4 \%$ and $19.9 \%$ respectively.

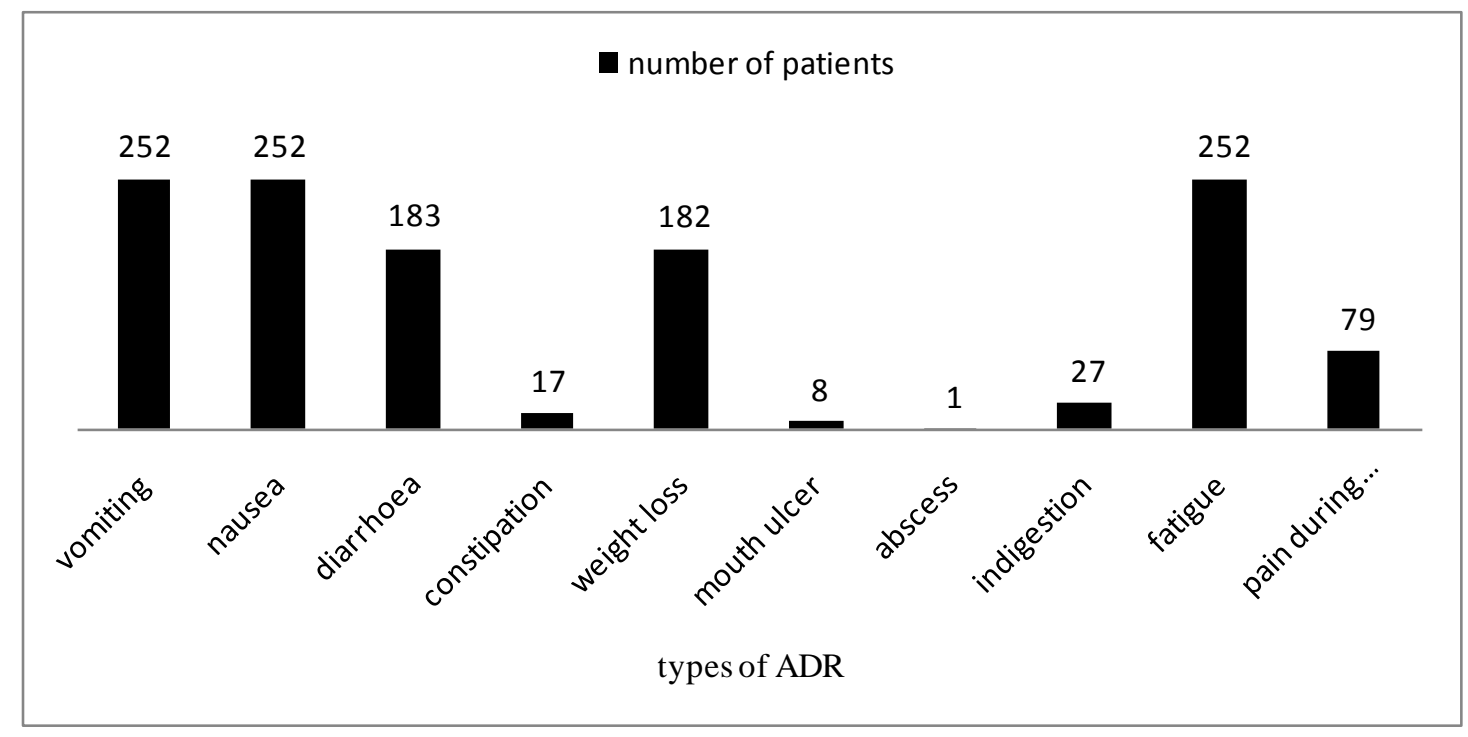

Fig 2: ADR's affecting Gastro-intestinal system

Majority of the ADRs reported were fatigue, nausea and vomiting. Pain during defecation was treatment specific (radiation therapy) for cervical cancer.

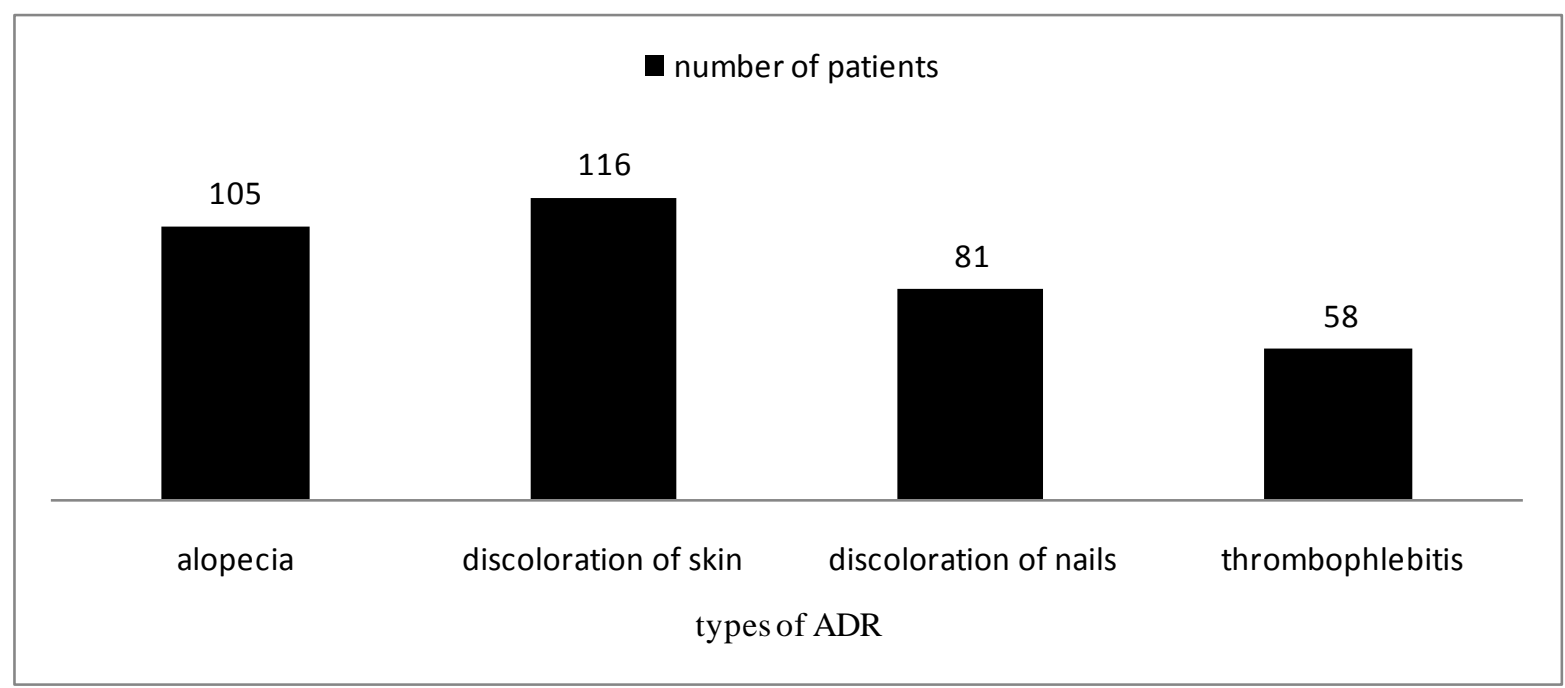

Fig 3: ADR's affecting skin and appendages 
Among 360 ADR's affecting skin and appendages, $32.2 \%$ were of discoloration of skin and $29.1 \%$ were of alopecia. Out of 140 ADR's affecting central nervous system, majority of the ADR's reported were of sleeplessness with $38.57 \%$. Out of 30 ADR's affecting respiratory system, majority of the patients had cough accounting $40 \%$. Bleeding followed by anaemia were commonly reported ADRs affecting circulatory system.

Table 6: Causality assessment of the collected ADR's:

\begin{tabular}{|l|l|l|}
\hline Parameter & Number of patients & \% \\
\hline Definite & 1273 & 54.3 \\
\hline Probable & 863 & 36.8 \\
\hline Possible & 206 & 8.7 \\
\hline Total & 2342 & 100 \\
\hline
\end{tabular}

Causality assessment of ADR's was done by using Naranjo scale. Out of 2342 ADR's reported, majority of the ADR's were categorized as definite with $54.3 \%$ followed by $36.8 \%$ being probable. All the ADRs collected were categorized into mild, moderate, severe by using severity scale (Hartwig and siegel scale).

Table 7: Distribution of adverse drug reactions based on severity scale

\begin{tabular}{|l|l|l|}
\hline Parameter & $\begin{array}{l}\text { Number of adverse drug } \\
\text { reactions }\end{array}$ & $\%$ \\
\hline Mild & 312 & 13.3 \\
\hline Moderate & 1971 & 84.1 \\
\hline Severe & 59 & 2.51 \\
\hline Total & 2342 & 100 \\
\hline
\end{tabular}

Among 2342 collected reactions, 84.1\% of ADR's were moderate followed by mild with $13.3 \%$. As the severity scale increases it becomes difficult to treat the adverse drug reaction and is not avoidable.

\section{DISCUSSION:}

In 2018, an estimated 1,735,350 new cases of cancer will be diagnosed in the United States and 609,640 people will die from the disease. The most common cancers (listed in descending order according to estimated new cases in 2018) are breast cancer, lung and bronchus cancer, prostate cancer, colon and rectum cancer, melanoma of the skin, bladder cancer, nonHodgkin lymphoma, kidney and renal pelvis cancer, endometrial cancer, leukaemia, pancreatic cancer, thyroid cancer, and liver cancer [24].

The number of new cases of cancer (cancer incidence) is 439.2 per 100,000 men and women per year (based on 2011-2015 cases). The number of cancer deaths (cancer mortality) is 163.5 per 100,000 men and women per year (based on 2011-2015 deaths). Cancer mortality is higher among men than women (196.8 per 100,000 men and 139.6 per 100,000 women). When comparing groups based on race/ethnicity and sex, cancer mortality is highest in African American men (239.9 per 100,000) and lowest in Asian/Pacific Islander women (88.3 per $100,000)$ [24].
In our study, mean age group affected with cancer was 51-60 years which is similar to a study conducted by Sharma et al [25].The most common cancers diagnosed were cervical cancer followed by breast cancer. The treatment for various cancers was as per NCCN guidelines except for receptor positive breast cancer.

In a study conducted by Sharma et al 2015, 500 ADR's were identified and recorded in the study subjects which is in contrast to our study where 2342 ADR's have been identified and reported. This change might be due to the difference in the sample size and change in the chemotherapeutic regimens [25].

In Anju Prasad et al study 2013, the number of chemotherapeutic patients developing ADR's were $86.53 \%$ which is in contrast to our study where $53.9 \%$ of patients treated with chemotherapy developed ADR's [26].

In a study conducted by Julie birdie Wahlang 2017, majority of the ADRs observed were related to gastrointestinal system, which is similar to our study [8]. The reason being, Cytotoxic chemotherapy agents have a direct effect on the GI mucosa causing inflammation, oedema, ulceration and atrophy (H.Jervoise N Andreyev et al, 2011).

In a study by Chopra et al 2016, haematological side effects were found to be $23.2 \%$. In contrast to our study, side effects were found to be $1.66 \%$ [23].

\section{Causality assessment:}

Manohar et al 2016 had used causality assessment scale (NARANJO scale) and categorized $49.5 \%$ of ADR's as 'possible', $50.5 \%$ as 'probable' which is in contrast to our study where $54.3 \%$ were definite, $36.8 \%$ were 'probable', $8.7 \%$ were 'possible'. This is important to know because most of the ADR's in hospitalized oncology patients are predictable and at least probably preventable. This can also bring awareness about probability of development of ADR's by anti-neoplastic agents [27].

\section{Severity assessment:}

Chopra et al 2016, stated that $86.9 \%$ of ADR's were categorized as mild, $12.8 \%$ as moderate, $0.17 \%$ as severe as per hartwig and siegel scale which is in contrast to our study where $13 \%$ were mild, $84 \%$ were moderate and $2 \%$ severe [23]. 


\section{Alopecia:}

In a study by Surendiran et al 2010, 51 of patients treated with cisplatin developed alopecia. Where as in our study, majority of the patients treated with cyclophosphamide developed alopecia. This may be due to metabolite aldophosphamide of cyclophosphamide causing alopecia [28].

\section{Nausea and vomiting:}

Nausea and vomiting are very common side effects of chemotherapeutic agents. In Chopra et al study 2016, nausea and vomiting were the most commonly observed ADR and it is similar to our study [23]. This may be due to chemotherapeutic agents induce vomiting by both central action on the chemoreceptor trigger zone (CTZ) and peripheral action on the gastrointestinal tract. The dominant receptors in the CTZ located on the floor of the fourth ventricle are serotonin type 3 (5HT-3) and dopamine type 2 (D2) which are involved in the mechanism of acute onset of vomiting.

In a study conducted by Julie birdie wahlang et al 2017, high-risk emetogenic drugs such as cisplatin and cyclophosphamide were premedicated by granisetron 3 $\mathrm{mg}$, ranitidine $50 \mathrm{mg}$ and dexamethasone $8 \mathrm{mg}$ which is in contrast to our study where only ondensetron $16 \mathrm{mg}$, dexamethasone $8 \mathrm{mg}$ were given. Affordability is the reason for prescribing ondansetron in our hospital [8].

In a study by Julie birdie wahlang 2017, moderate emetogenic drugs such as paclitaxel, carboplatin, doxorubicin and oxaliplatin were premedicated with ondansetron $16 \mathrm{mg}$, dexamethasone $8 \mathrm{mg}$ and pantoprazole $40 \mathrm{mg}$ [8]. It is in contrast to our study where only ondensetron $16 \mathrm{mg}$ and dexamethasone $8 \mathrm{mg}$ are given.

\section{Anal pruritis:}

In a study done by Chopra et al 2016, $2.5 \%$ patients developed anal pruritis which is in contrast to our study where all the cervical cancer patients developed anal pruritis. This might be because of the side effect of chemoradiation given to treat cervical cancer [8].

As per Murugah Swamiappan et al 2016, anogenital pruritis is treated by maintaining proper genital hygiene. Comfortable absorptive cotton innerwear should be chosen instead of tight fitting synthetic materials. Tampons are considered better than sanitary pads during menstruation. Severe scratching may lead to excoriations, lichenification and depigmentation. Oozing excoriated lesions may get infected hence requires topical or systemic antibiotics and astringent soaks like aluminium acetate. The mainstay of treatment for nonspecific anogenital pruritis is topical steroids like clobetasol propionate $0.05 \%$ which is similar to our study [29].

\section{Radiation-induced skin reactions:}

In our study, $32.2 \%$ developed radiation induced skin reactions. It is dose-dependent and might be due to the decrease in functional stem cells, changes in the skin endothelial cells, inflammation, skin-cell necrosis and death.
During or after radiation treatment, usage of metallicbased topical products (zinc oxide creams or deodorants with an aluminium base) must be avoided because they might increase the surface dose to skin. Loose-fitting clothing should be worn over the irradiated area to prevent friction injuries. Clean and dry irradiated area should be maintained. Extreme temperatures and the use of starch-based products must be avoided as they increase the risk of infection. In our study, patients treated with radiation therapy were counselled regarding the above preventive measures.

\section{Weight loss:}

In our study $7.7 \%$ patients had weight loss because of integrated physiological response of substrate mobilization driven by inflammation that causes an increase in pro-inflammatory cytokine activity during cancer progression.

\section{Fatigue:}

According to NCCN guidelines by Ann M. Berger et al 2017 for cancer related fatigue, general strategies such as use of distractions (e.g., games, music, reading, socializing), yoga, physically based therapy (massage therapy), psychological interventions like cognitive behavioural therapy and limit naps to $<1$ hour to not interfere with night time sleep quality can be applied. In our study, $10.7 \%$ patients had fatigue [30].

In our study $0.3 \%$ had oral mucositis and $7.8 \%$ had diarrhoea. This might be due to radiation therapy.

Pharmacist participation with the medical team in oncology unit contributes to a significant reduction in preventable ADR's. Many ADR's have not been brought to the notice of the health care professionals due to lack of spontaneous reporting. Majority of the adverse effects can be minimized with proper counselling and monitoring. For example, to overcome the side effects of cervical cancer treatment, patients are to be counselled about the use of materials during menstrual cycles, genital hygiene, avoiding of starch based powders and solutions. Patient counselling is a very important activity of the clinical pharmacist in which they counsel regarding the types of treatment, its adverse effects and management of ADR's. Counselling about ADR's can either decrease the hospital stay or the expenditure. Counselling to care takers can create an awareness regarding the risk factors, symptoms and specific screening tests that help in early detection of cancer. In terminally ill cancer patients, as a part of palliative treatment moral support has to be given.

The presence of clinical pharmacist in oncology department will help in the identification of medication errors, if not corrected they would have worsened the condition of the patients and affect the quality of life. In our study 3 interventions were made:

- In a colon cancer patient, FOLFOX (5FU+oxaliplatin) regimen was used. Peripheral neuropathy was reported in a patient treated with oxaliplatin. When it was brought to the notice of the doctor, the drug has been discontinued. 
- In a patient with carcinoma of tongue, before beginning of chemotherapy she was not pre-medicated with ondansetron, which lead to severe nausea and vomiting. This might be due to the negligence of the nursing staff.

- Instead of administrating carboplatin to an ovarian cancer patient, cisplatin was given. When it is identified and reported, the cisplatin solution was decanted and carboplatin was administered.

In our study, with the presence of clinical pharmacist in oncology, majority of the patients were counselled regarding the adverse effect of the drugs and the precautions to be taken. This has helped in improving the awareness, medication adherence in the patients.

\section{CONCLUSION:}

Almost all the patients attending the radiotherapy department and receiving cancer chemotherapy

\section{REFERENCES:}

1. Mohandas $k$ mallath, David G taylor, Rjendra A Badwe, Goura K Rath, V Shanta, CS Pramesh, Raghunadhara Digumarti, Paul Sebastian et al. The growing burden of cancer in india: epidemiology and social context. 2014(14)70115-9.

2. Rajender A. Badwe, Rajesh dikshit, M.laversanne and Fredie bray. Cancer incidence trends in India. Jpn J Clin Oncol 2014; 44(5)401-407.

3. Sapan Kumar Behera, Chenchu Reddy Kishtapati, Vikneswaran Gunaseelan, Biswajit Dubashi, Adithan Chandrasekaran, Sandhiya Selvarajan. Chemotherapy Induced Adverse Drug Reactions in Cancer Patients in a Tertiary Care Hospital in South India. J Young Pharm, 2017; 9(4): 593-597.

4. Alison Pearce, Marion Haas, Rosalie Viney, Sallie-Anne Pearson, Philip Haywood, Chris Brown, Robyn Ward. Incidence and severity of self-reported chemotherapy side effects in routine care: A prospective cohort study. PLOS ONE; 2017:10

5. Rajamanickam Baskar, Kuo Ann Lee, Richard Yeo and Kheng-Wei Yeoh. Review Cancer and Radiation Therapy: Current Advances and Future Directions. Int. J. Med. Sci. 2012, International Journal of Medical Sciences 2012; 9(3):193-199.

6. World health organisation. International drug monitoring: the role of the hospital, Geneva: world health organisation; 1996.

7. Jeffery S Russell \& A Dimitrios Colevas. Adverse event monitoring in oncology clinical trials- Review: Clinical Trial Methodology; Clin. Invest. 2013; 3(12):1157-1165.

8. Julie Birdie Wahlang, Purnima Devi laishram, Dhriti Kumar Bramha, Chayna Sarkar, Joonmoni Lahon and Banylla Shisha Nongkynrih. Adverse drug reactions due to cancer chemotherapy in a tertiary care teaching hospital. Ther Adv Drug Saf, 2017; 8(2):61-66.

9. A. Blenkinsopp, P. Winkle, M.Wang and P.A. Routledge. Patient reporting of suspected adverse drug reactions: a review of published literature and international experience. Br J clin Pharmacol, 2016; 63:2; 148-156.

10. Mounika M.Review on: Adverse drug reactions of chemotherapeutic drugs. RRJPTS 2016; 4(3).

11. Munir Pirmohamed, Alasdair $M$ Breckenridge, Neil $R$ Kitteringham, B Kevin Park. Adverse drug reactions. BMJ, 1998; 316:25.

12. Ram kumar sahu, rajni yadav, pushpa Prasad, amit roy and shashikant chandrakar. Adverse drug reactions monitoring, developed ADRs. All the age groups were equally affected. Majority of the ADRs were definite and moderate in severity. Proper awareness regarding identification of adverse drug reactions among health care professionals and patients are necessary. Use of preventive measures and early detection of adverse drug reactions has the potential to reduce the severity of the ADRs. Hence, pharmacovigilance in India need to be put in place to reduce the burden of adverse effects and thereby improve the health of the patients. Our study highlighted the importance of clinical pharmacist in oncology department by counselling the patient regarding the early signs and symptoms, adverse effects of various treatment modalities, its identification and management and also in finding few medication errors regarding anti-neoplastic agents.

13. prospects and impending challenges for pharmacovigilance. springer plus 2014;3:695.

14. Marília Berlofa Visacri, Cinthia Madeira de Souza, Rafaela Pimente, Cristina Rosa Barbosa. Pharmacovigilance in oncology: pattern of spontaneous notifications, incidence of adverse drug reactions and under-reporting. Brazilian Journal of Pharmaceutical Sciences vol. 50(2); 2014.

15. Kirandeep Kaur, Megha Sood, Shivani Bhagat, Tarundeep Singh, Mukta Jain, Deepty Arora, JS Sekhon, Sandeep

16. Kausha. Spontaneous adverse drug reaction monitoring in oncology: Our experience. Indian Journal of Cancer 2015; 52(3).

17. Arulmani $R$, Rajendran SD, Suresh B. Adverse drug reaction monitoring in a secondary care hospital in south India. Br J clin Pharmacol 2008; 65:210-6.

18. Vishal R. Tandon, vivek mahajan, vijay khajuria, zahid gillani. Under reporting of adverse drug reactions: A challenge for pharmacovigilance. Indian journal of pharmacology, 2015; 47 (1).

19. Van Grootheest, A.C.Jong-Van den berg, L.T.W. van. The role and community pharmacists in pharmacovigilance. Res. Social Adm. Pharm., 2005; 1(1); 126-133.

20. Gandhi, T.K.; Bartel, S.B.; Shulman, L.N; Verrier, D.; Burdick, E.; cleary, A.; Rothschidl, J.M.; Leape.; Bates, D.W. Medication safety in ambulatory chemotherapy setting. Cancer, 2005; 104(11):2477-2483.

21. Lau, P.M.; Stewart, K.; Dooley, M.The ten most common adverse drug reactions (ADRs) in oncology patients: do they matter to you? Support. Care Cancer, 2005; 12(9); 626-633.

22. Cobert, B.L.; Biron P. Pharmacovigilance from A to Z: adverse drug event surveillance. Massachussets: Blackwell Science, 2002; 235.

23. Liekweg, A.; Westfeld, M.; Jaehde, U. From oncology pharmacy to pharmaceutical care: new contributions to multidisciplinary cancer care- Support. Care Cancer, 200412(2):73-79.

24. Iihara, H.; Ishihara, m.; Matsuura, K.; Kurahashi, S.; Takahashi, T.; Kawaguchi, Y.; Yosida, K.; Itoh, Y. Pharmacists contribute to the improved efficiency of medical practices in the outpatient cancer chemotherapy clinic. J. Eval. Clin. Pract.2011; 18 (4)1-8.

25. Deepti chopra, Harmeet S. Rehan, vibha Sharma, Ritu mishra. Chemotherapy-induced adverse drug reactions in oncology patients: A prospective observational survey. Indian journal of medical and paediatric oncology 37(1).

26. https://www.cancer.gov/about- cancer /understanding /statistics. 
27. Ajitha Sharma, K. Meena Kumar, Hasitha Diana Manohar K.L.Bairy, Joseph Thomas. Pattern of adverse drug reactions due to cancer chemotherapy in a tertiary care hospital in south India. Perspectives in clinical research April-June 2015; 6(2).

28. Anju Prasad, Pratyay pratim data, Jibak bhattacharya, Chaitali pattanayak, Ashok singh chauhan and Parbaty panda. Pattern of adverse drug reactions due to cancer chemotherapy in a tertiary care teaching hospital in eastern India. J pharmacovigilance 2013;1-2.

29. Hasitha Diana Manohar, Shalini Adiga, Joseph Thomas, Ajitha Sharma. Adverse drug reaction profile of microtubule-damaging antineoplastic drugs: A focused pharmacovigilance study in India. Indian journal of pharmacology, 2016; 48(5).

30. Surendiran. A, N.Balamurgan, K.Gunaselan, Shahid Akhtar, K.S. Reddy, C.Adithan. Adverse drug reaction profile of cisplatin-based chemotherapy regimen in a tertiary care hospital in India: An evaluative study. Indian J Pharmacol ,2010; 42(40-43).

31. Swapnajaswanth $M$, suryanarayana S. P., suman G., Murthy N.S. A study to assess select risk factors for carcinoma cervix among patients attending kidwai memorial institute of oncology. Int J Community Med Public Health 2017; 4(11):4238-4243.

32. Ann M. Berger. NCCN clinical practice guidelines in oncology guidelines for cancer related fatigue. 2017 